\title{
Resilience in a Mexican Pacific Mangrove after Hurricanes: Implications for Conservation Restoration
}

\author{
Mateo D. M. Ruiz Bruce Taylor ${ }^{1 *}$, José Luis Rangel-Salazar ${ }^{1}$, Bonifacio Cortés Hernández ${ }^{2}$ \\ ${ }^{1}$ Department of Biodiversity Conservation, El Colegio de la Frontera Sur, San Cristóbal de Las Casas Campus, Chiapas, Mexico; \\ ${ }^{2}$ Reforestation Nursery, Servicios Ecoturísticos La Ventanilla Cooperative Society, Puchutla, Mexico. \\ Email: *truiz@ecosur.edu.mx
}

Received September $27^{\text {th }}, 2013$; revised October $28^{\text {th }}, 2013$; accepted November $24^{\text {th }}, 2013$

Copyright (C) 2013 Mateo D. M. Ruiz Bruce Taylor et al. This is an open access article distributed under the Creative Commons Attribution License, which permits unrestricted use, distribution, and reproduction in any medium, provided the original work is properly cited. In accordance of the Creative Commons Attribution License all Copyrights @ 2013 are reserved for SCIRP and the owner of the intellectual property Mateo D. M. Ruiz Bruce Taylor et al. All Copyright (C) 2013 are guarded by law and by SCIRP as a guardian.

\begin{abstract}
High resilience is a mangrove trait that is compatible with life in a dynamic environment, however, catastrophic disturbance can lead to the entire forest structure being re-defined. In the Pochutla district of Oaxaca, two hurricanes made landfall in 1997 and one more in 2012. Following the 1997 hurricanes, extensive mangrove restoration was carried out in the study area. A cohort of Rhizophora mangle saplings planted in 2007 showed $10 \%$ mortality during the first year after transplantation, an average growth of $39 \mathrm{~cm}$, and a positive association between growth rate and the level of water in the lagoon. Following Hurricane Carlotta of 2012, measurements of structural impact and tree mortality were taken in restored $R$. mangle stands and in naturally regenerated patches of Laguncularia racemosa. The role of tree girth in $R$. mangle susceptibility to wind damage was also investigated. The stands of $R$. mangle suffered $80 \%$ reduction in stem density and $86 \%$ loss of basal area, whereas the corresponding values for $L$. racemosa were $26 \%$ and $15 \%$, respectively. Within stands of $R$. mangle, mortality conserved a positive relationship with structural impact categories and the frequency of snapped stems was segregated across girth classes. The results suggest that $L$. racemosa has greater resilience to hurricane damage, which has some consistency with previous research and implications for conservation restoration protocols. In order to promote a system with higher resilience, we recommend an on-going restoration effort with mixed mangrove species.
\end{abstract}

Keywords: Coastal Lagoon; Disturbance; Hurricane; Mangrove; Restoration; Resilience

\section{Introduction}

Ecological communities vary in their resilience, differing in their tolerance to disturbance and their response when that tolerance is exceeded. Mangrove trees display traits that are characteristic of pioneer species, such as fast colonization, yet they can form mature ecosystems [1]. In its mature phase, a mangrove forest has stored, accumulated energy, its canopy excludes most competitors [2], and it is deceptively stable. However, when the forest is subjected to disturbance of sufficient magnitude, a limit to its ecological resilience is met and the entire system may redefine its structure, shifting to a new stability domain. Changes between functionally different states and the existence of multiple equilibria define ecosystem

${ }^{*}$ Corresponding author. response to disturbance [3]. The brittleness and accumulated capital of a mature mangrove stand make it prone to transition from stability to catastrophe, and in this sense it is an accident waiting to happen [4].

Hurricanes are catastrophic disturbance events that can both disrupt and modify ecosystems [5]. A disturbance of this magnitude can precipitate a sudden release of accumulated ecological capital and this new phase has been termed creative destruction [4]. In mangroves, post-hurricane dead biomass may exceed $150 \mathrm{t} / \mathrm{ha}$, which represents an estimated $570 \mathrm{k}$ of nitrogen and $180 \mathrm{k}$ of phosphorus that are newly available for ecosystem processes [6]. During the subsequent reorganization phase, species-specific dispersal capabilities may alter the future trajectory of the community [7] and changes in mangrove species composition sometimes ensue [6]. The exploita- 
tive phase of successional development is characterized by high ecological resilience and rapid growth [4]; it may also be affected by management decisions that respond to the initial disturbance.

The immediate impact of hurricanes on mangrove structure varies. After category 4 Hurricane Charley in 2004, $47 \%$ initial mortality was reported for mangrove trees of over $5 \mathrm{~cm}$ diameter at breast height (DBH) [7]. Also from Florida, blow downs of 50\% - 100\% biomass were recorded within the eye path of category 5 Hurricane Andrew in 1992 [8]. Alternative estimates for the same hurricane report $80 \%$ - 95\% of trees lost [6]. The DBH apparently affects the probability of wind damage. For example, after Hurricane Charley larger trees were more heavily impacted, with a significant difference reported between individuals $<5 \mathrm{~cm}$ and $>5 \mathrm{~cm}$ DBH [7]. In the case of Hurricane Andrew, mangrove trees with $>30 \mathrm{~cm}$ DBH exhibited decreased mortality, as did mangroves of $<5 \mathrm{~cm}$ DBH [6]. Despite this consistency, mortality was not strongly segregated across trees sizes following category 3 Hurricane Georges in the Dominican Republic [9].

Focusing on comparisons between Rhizophora mangle (Red mangle) and Laguncularia racemosa (White mangle), there appears to be limited consistency in species-specific mangrove response to wind damage. After Hurricane Georges, $R$. mangle suffered 50\% mortality in stems and $47 \%$ reduction in basal area, whereas $L$. $r a$ cemosa suffered $26 \%$ and $25 \%$ loss in stems and basal area, respectively [9]. In some other cases, with greater wind speeds, no difference was evident between these species [6-8]. There is also evidence that $L$. racemosa sustained greater initial impact than $R$. mangle and Avicennia germinans in samples taken outside the eyepath, where wind speeds reached $40 \mathrm{~m} / \mathrm{s}$ [8]. Taking species in conjunction with size classes, $L$. racemosa with a DBH of $20-25 \mathrm{~cm}$ have been identified as more prone to hurricane damage and larger $R$. mangle individuals (>35 cm DBH) have been shown to be less susceptible [9].

Understanding species-specific mangrove responding to hurricane damage may help to identify vulnerable stands or guide post-hurricane restoration. However, a rural community's response to hurricane impact on their forest assets is another significant factor in the processes that follow the initial disturbance. One response is opportunistic land settlement of areas that were previously forested [10], which can lead to forests being permanently cleared for agricultural purposes. In Mexico, land transformation has been signalled as one of the most serious threats to the conservation of terrestrial wildlife and ecosystems [11] and is a process that has been historically fuelled by agro-pastoral policies [12]. The clearcutting of mangroves for agriculture and aquiculture is a considerable threat throughout the tropics [13] and Mexico is no exception. A more sustainable response to hurricane impact on tropical forests would be to exploit fallen trunks, and this practice has been recommended in conjunction with pruning to inhibit disease and management to reduce the risk of forest fires [14]. Despite the pragmatic appeal of such adaptive management, the opening up of new intrusion routes to extract recovered timber also provides access to other extractable resources, such as wildlife [10].

Alternatively, conservation restoration programmes can be initiated. Among marine systems, mangroves may be relatively easy to reconstruct because of the plasticity of their growth, the presence of viviparous seedlings, and the good survival and growth rates of these seedlings in the absence of adults [15]. Restoration of degraded mangroves was promoted by several Indian Ocean governments following the 2004 Asian tsunami, in recognition of the role of mangroves as barriers to natural disasters [16]. However, the explicit link between hurricanes, mangrove restoration and mangrove ecosystem services is not well documented; rather it is a connection which has as yet un-tapped potential.

Hurricane landfalls are infrequent on the Pacific coast of Mexico, compared to the Gulf or Caribbean [9], and information on hurricane impact on mangroves reflects this tendency. In this study, we examine the relatively small, hurricane-impacted mangrove of the coastal lagoon La Ventanilla in the southern Mexican Pacific region. In the rural community of La Ventanilla, Hurricanes Pauline and Rick of 1997 were the first catastrophic disturbances within living memory, registering categories 4 and 1 on the Saffir/Simpson scale, respectively $[17,18]$. Hurricane Pauline reached peak intensities of $59 \mathrm{~m} / \mathrm{s}$ on the $7^{\text {th }}$ and $8^{\text {th }}$ of October, at which point the centre of the cyclone was close to La Ventanilla [17]. The majority of mangrove trees were destroyed and the tidal inlet ceased to open until 2010. This change in hydrology may have been precipitated by the accumulation of dead trees and branches along the barrier beach after the hurricanes (obs. pers.).

During 1998, approximately 45,000 R. mangle seedlings were established in a government-subsidized community-managed tree nursery in La Ventanilla, and these were planted out approximately one year after the hurricanes. A further 25,000 saplings were propagated and planted between 1999 and 2001, and 10,000 more between 2007 and 2008. The original intention was to develop forestry resources, but this was superseded by a community-based ecotourism management project in the mangrove [19]. In 2010, sampling in four $300 \mathrm{~m}^{2}$ quadrats of $R$. mangle suggested good recovery, with an average stand height of $17.9 \mathrm{~m}$ and a basal area of 37.5 $\mathrm{m}^{2} / \mathrm{ha}[20]$. 
Such active forest management can strongly influence the character of mangrove stands in terms of species composition, stem density and age structure. The coupling of information from hurricane impacts with recommendations for reforestation practices is a logical step towards conserving these ecosystems. In La Ventanilla, a more recent hurricane provided an opportunity to evaluate hurricane impact on restored mangroves. Carlotta was a strong category 2 hurricane which reached maximum intensity at $21: 00$ on June the $15^{\text {th }}$, 2012, and made landfall at 01:00 the following day. Wind speed reached an estimated $49 \mathrm{~m} / \mathrm{s}$ at peak intensity, at which pointed the hurricane centre was approximately $30 \mathrm{~km}$ from La Ventanilla [21].

The objectives of this study were to evaluate the reforestation that followed Hurricane Pauline, to determine whether $R$. mangle or $L$. racemosa sustained greater structural impact and mortality following Hurricane Carlotta, to investigate the role of tree girth in susceptibility to wind damage, and to consider how best to proceed with ecological restoration following this more recent event. This report stands out because of the antecedent of restoration, the study area's geographical position and its geomorphological context.

\section{Methodology}

\subsection{Study Area}

The southern Mexican Pacific is characterized by highrelief flanks of coastal ranges, where water sheds tend to be narrow and produce rivers with small drainage basins and small volumes [22]. The region has numerous small coastal lagoons, predominately of a barred inner shelf type [22]. The coastal lagoon of La Ventanilla is in Oaxaca's southernmost district of Pochutla, located between the parallels $15^{\circ} 40^{\prime} 26.64 " \mathrm{~N}$ and $96^{\circ} 34^{\prime} 53.08^{\prime \prime} \mathrm{W}$, on a narrow coastal plain running roughly east-west between the Sierra Madre Sur and the Pacific Ocean.

Based on precipitation data from 1961 to 1990, this study area is within a region with an average total rainfall of $646 \mathrm{~mm}$ per year, and an average of $91 \%$ of this rainfall occurs between May and October [23]. Tropical cyclones produce extreme rainfall events that contribute a relatively high amount to the annual total [23]. Average temperatures exceed $26^{\circ} \mathrm{C}$ and the regional climate is classified as warm sub-humid [24].

Approximately 50 ha of $L$. racemosa dominated mangrove are distributed in a narrow strip on the seaward side of the lagoon, either side of an ephemeral tidal inlet. Towards the west $R$. mangle gradually replaces $L$. $r a$ cemosa, occupying a further 20 ha. About 700 m inland a patch of $\sim 100$ ha of $R$. mangle borders a channel of permanent water and extends across a shallow drainage basin which receives numerous intermittent water courses.
The lagoon itself is a coastal depression [22] and seasonal vertical flow predominates over lateral flow. Although these attributes are consistent with a basin mangrove [25], some structural aspects of the mangrove are suggestive of a riverine system [26]. The surrounding landscape is dominated by tropical dry forest, with some agricultural land and few villages.

\subsection{Restoration and Hydroperiod}

Approximately $500 R$. mangle saplings were planted between late November and early December of 2007 in an area of 0.1 ha. Propagules had been established in a nursery approximately one year prior to planting and the growth rate of a cohort of 56 randomly selected saplings was monitored for 50 weeks after planting. The individuals were marked, mapped, and their height was measured at the tip of the highest leaf scale every 22 days. Saplings that died were censored from the height results. In December 2009 the mortality of the marked trees was assessed and in May 2013, almost one year after Hurricane Carlotta, the DBH, height and highest root height of 20 individuals was measured within the same 0.1 ha plot.

Water level fluctuations were measured from a fixed quay every two days for 388 days from December the $11^{\text {th }} 2007$. Water depth in relation to reforested saplings was based on three bore holes located among the reforested trees. To evaluate a possible relationship between water level and growth rate, the difference between the average water depths of consecutive 22-day periods was regressed onto the difference between successive height measurements of saplings.

\subsection{Impact of Hurricane Carlotta}

Ten $100 \mathrm{~m}^{2}$ quadrats were established at specific sites of on-going ornithological monitoring, thus ensuring a selection process independent of the degree of damage sustained locally. Seven quadrats were in $R$. mangle stands and three in $L$. racemosa. In no quadrats were $L$. racemosa and $R$. mangle encountered together and in all cases the mangle species were dominant, with an average relative frequency of $0.96(\sigma=0.08)$. Seven quadrats were mono-specific, while the remaining three contained relative frequencies of $0.09,0.11$ and 0.22 of Pithecellobium sp., none of which were over $6.5 \mathrm{~cm}$ DBH. Only trees of $R$. mangle and L. racemosa are included in the analyses.

Trees within the quadrats were judged as dead or alive and assigned to one of three structural impact categories: standing, fallen or snapped. DBH measurements were recorded; for $R$. mangle, these were taken $30 \mathrm{~cm}$ above the highest prop root of the trunk [27]. The distance to the nearest neighbour was measured and in the case of snapped trees the height of the breakage was recorded. 
For snapped $R$. mangle, the height of the uppermost aerial root was measured to provide the means with which to analyse the anchorage system associated with this phenomenon.

Pre-hurricane stem density (trees per hectare) was estimated for each species by including all structural impact categories [8] and extrapolating from the quadrat areas. The $\mathrm{DBH}$ of mangrove stands of $R$. mangle were compared with those of L. racemosa, using the MannWhitney $U$-test due to non-normal distributions in both variables (Shapiro-Wilks $W=0.943$ for $R$. mangle, $P<$ 0.001 ; $W=0.717, P<0.001$ for $L$. racemosa). Both species were characterized in terms of spatial pattern using indices of aggregation obtained with nearest-neighbour methods [28].

As a measure of hurricane impact, percentage reductions of stem density and basal area were calculated for stands of $R$. mangle and $L$. racemosa [8,9]. This percentage varies depending on the reference used for the post hurricane forest. Given the delayed mortality in hurricane-impacted mangroves [6,8], standing trees were used as a conservative reference for the remaining forest, with windblown trees excluded. In the case of $R$. mangle some standing trees were already dead and, for this species, reductions for both total standing trees and only live standing trees are reported.

The structural impact categories were codified on an ordinal scale $(1=$ standing, $2=$ fallen and $3=$ snapped $)$ and a Mann-Whitney $U$-test was used to compare the impact sustained by stands of $L$. racemosa with that of $R$. mangle. The $U$-test was also used to compare mortality between species $(1=$ alive and $2=$ dead). Within each structure damage class, a paired Wilcoxon test was performed to gauge the significance of differences between numbers of live and dead trees for each species. These distribution free statistical methods were selected after testing the variables for normality using $\alpha=0.05$ for the Shapiro-Wilk test and adjustment for ties were made in both cases.

Because many fallen trees were either alive, were brought down by other trees, or both, the DBH of snapped trees was used as a measure of size-class vulnerability to wind damage. Analysis was not feasible for L. racemosa, due to the small number of snapped individuals. The distribution of DBH size-classes for snapped $R$. mangle individuals was statistically analysed using a chi-squared goodness-of-fit test [9]. First, the DBH measurements for $R$. mangle from all structural impact categories was divided into two groups of three quadrats each and separated into $2 \mathrm{~cm} \mathrm{DBH}$ classes (2.5- 4.49, 4.5 - 6.49...20.5 $22.49>22.5)$. These groups were conveniently of equal size $(n=98)$ and represent two un-impacted areas of mangrove. The chi-squared test null hypothesis was that the distribution of $\mathrm{DBH}$ size classes did not differ be- tween these two groups. Secondly, to test a null hypothesis that the observed size-class distribution of snapped trees did not differ from the expected distribution from an un-impacted mangrove, DBH classes of snapped trees from four quadrats were compared to DBH classes of all impact categories from two quadrats (minus one random individual to obtain equal group sizes). In this test the unequal number of quadrats was used to obtain a larger sample of snapped trees $(n=64)$. Thus, data from separate quadrats was used for both comparisons between distributions to avoid violating the assumption of independence between variables.

Structural impact categories within species were compared in terms of $\mathrm{DBH}$ and distances to nearest-neighbour, excluding snapped $L$. racemosa individuals due to the small sample size of that group. Using an $\alpha=0.05$ for the Shapiro-Wilk test, parametric tests were ruled out due to non-normality and a ties-adjusted Mann-Whitney $U$ test was therefore used. The height at which trees snapped was considered a relevant parameter of impact due to its bearing on re-growth from remaining limbs, i.e. trees snapped higher up should have a better chance of retaining limbs that will potentially re-sprout. Therefore, for snapped $R$. mangle associations were sought between the breakage height and the height of the last aerial root, $\mathrm{DBH}$ and distance to nearest-neighbour. For breakage height the Shapiro-Wilk test indicated a non-normal distribution $(P<0.001)$ and the Spearman rank order correlation was therefore used.

\section{Results}

\subsection{Restoration and Hydroperiod}

The total growth of saplings over 50 weeks was $38.55 \mathrm{~cm}$ (3.34 cm per calendar month). A total of 15 saplings died in 2008 (9.6\%): 11 between the $30^{\text {th }}$ of January and the $5^{\text {th }}$ of April, two in May and one in both November and December. Between January and December 2009 there were no further mortalities. By May 2013 average tree height in the sampled area was $5.39 \mathrm{~m}(\sigma=1.34)$, average $\mathrm{DBH}$ was $4.95 \mathrm{~cm}(\sigma=0.9)$ and the highest root averaged at $1.68 \mathrm{~m}(\sigma=0.31)$. Few snapped trees were observed in this restored area and foliage recovered quickly after Hurricane Carlotta.

The regression of sapling growth rate on changes in water level produced a significant correlation coefficient ( $r_{s}=0.69, P<0.01, N=16$ ). Water level rose rapidly after transplantation, due to the closure of the tidal inlet (Figure 1). This was followed by a gradual, constant drop over four months of dry season and drastic fluctuations during the rainy season. These fluctuations were most intense at the onset of the rains, with a maximum increase of $119 \mathrm{~cm}$ during 5 days from June $3^{\text {rd }}(23 \mathrm{~cm}$ per day). 


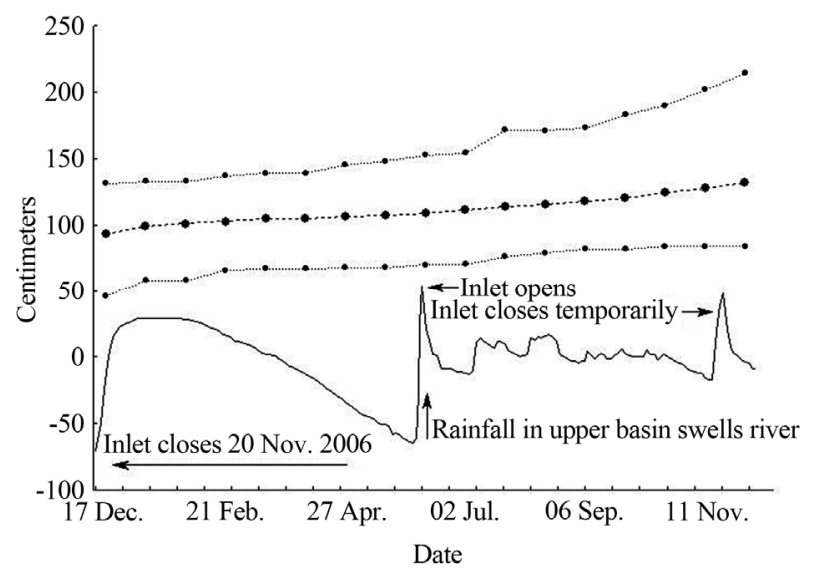

Figure 1. A one-year cycle of hydroperiod and sapling growth of reforested Rhizophora mangle at La Ventanilla, Oaxaca, southern Mexico from 2007-2008. Continuous line $=$ water level in relation to ground level; heavy dashed line = average height of 56 saplings; lighter dashed lines = minimum and maximum heights.

\subsection{Impact of Hurricane Carlotta}

Estimated pre-hurricane stem density was 5033 per hectare for $L$. racemosa and 2914 per hectare for $R$. mangle. There was a significant difference between the DBH of $L$. racemosa and $R$. mangle ( $U=12362$, two-tailed $P<$ 0.001 ) and rank sums indicate that, despite similar means, this variable was greater for $R$. mangle (L. racemosa mean $\mathrm{DBH}=10.14, \sigma=7.74$ and $R$. mangle mean $\mathrm{DBH}$ $=11.53, \sigma=6.01)$. The indices of aggregation were below unity for both species indicating a clumped spatial pattern $(R=0.55$ for $L$. racemosa and $R=0.83$ for $R$. mangle) and in both cases the difference between the observed and expected distance to nearest-neighbour was significant $(P<0.001 ; Z=-10.663$ for $L$. racemosa and $Z=-4.547$ for $R$. mangle).

For $L$. racemosa stem density was reduced by $25.9 \%$ (4000 trees per hectare post hurricane) and standing basal area was reduced by $15.2 \%$ (from $64.2 \mathrm{~m}^{2} / \mathrm{ha}$ to 54.4 $\mathrm{m}^{2} / \mathrm{ha}$ ). In stands dominated by $R$. mangle stem density was reduced by $79.9 \%$ counting all standing trees (586 trees per hectare post hurricane) and by $85.8 \%$ counting only live standing trees (414 trees per hectare). Standing basal area was reduced by $84 \%$ if all standing trees are included (from $38.6 \mathrm{~m}^{2} /$ ha to $6.2 \mathrm{~m}^{2} / \mathrm{ha}$ ) and by $88.4 \%$ if only live standing trees are counted (leaving post hurricane basal area at $4.5 \mathrm{~m}^{2} / \mathrm{ha}$ ).

Of the $151 \mathrm{~L}$. racemosa sampled, 120 were standing (79\%), 25 were fallen (17\%) and 6 were snapped (4\%). For $R$. mangle $n=204$, with 41 standing (20\%), 66 fallen (32\%) and 97 snapped (48\%). These species-specific impact percentages suggest that higher structural damage was sustained by $R$. mangle and the $U$-test comparison across all impact categories confirms a significant difference between the two species: one-tailed $P$ that struc- tural damage for $R$. mangle was greater than for $L$. racemosa is $<0.001$ ( $U=5243$ ). In terms of mortality, 145 $L$. racemosa were alive (96\%) and six dead, while for $R$. mangle 81 individuals were alive (40\%) and 123 dead (60\%). This difference in species-specific mortality is significant: one-tailed $P$ that $R$. mangle mortality is greater than that of $L$. racemosa is $<0.001(U=6727)$.

Within $L$. racemosa structural impact classes mortality was consistent: the only trees to die were broken and all broken trees died. Within $R$.mangle structural impact classes standing trees were significantly more likely to survive (29\% mortality, Wilcoxon paired test $Z=2.313$, 2-tailed $P<0.05$ ), fallen trees showed no significant difference (44\% mortality, $Z=0.856$, 2-tailed $P=0.39$ ) and snapped trees were significantly more likely to die (84\% mortality, $Z=5.788$, 2-tailed $P<0.001$ ).

In the comparison of all impact categories from two groups of $R$. mangle quadrants, the DBH size-class distributions did not differ significantly, regardless of which of the two samples was considered observed or expected $\left(X^{2}=8.736, P=0.56\right.$ and $X^{2} 8.99, P=0.53$; $\left.\mathrm{df}=10\right)$. The comparison between all impact categories (i.e. unimpacted mangrove) and dead snapped trees did produce a significant difference $\left(X^{2}=23.62, P<0.01, \mathrm{df}=10\right)$. Figure 2 shows which DBH size-classes produced the greatest errors.

No difference was observed in the DBH of standing or fallen trees for $L$. racemosa $(U=1461$, one-tailed $P=$ $0.42)$ or $R$. mangle $(U=1187$, one-tailed $P=0.14)$, but snapped $R$. mangle were thicker than both standing $(U=$ 1202, one-tailed $P<0.001)$ and fallen $(U=2167$, onetailed $P<0.001)$ trees of the same species. There was no

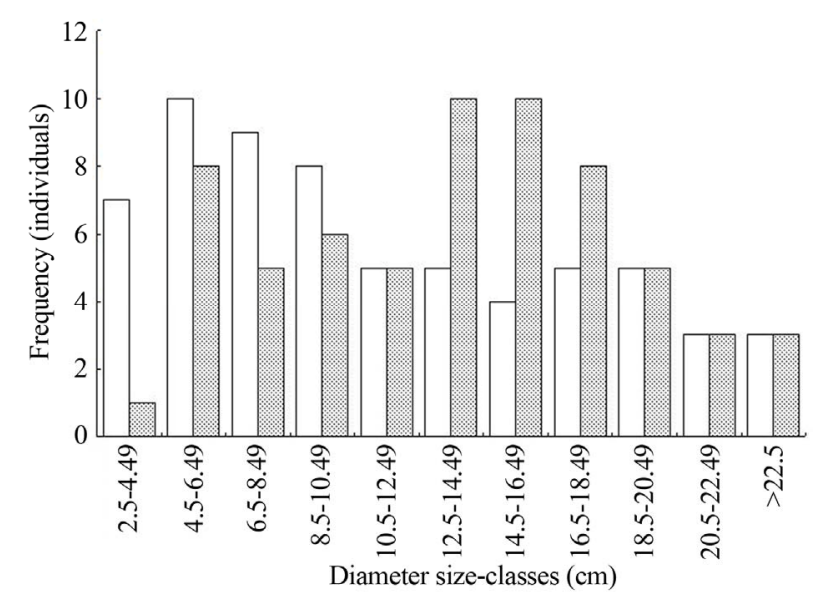

Figure 2. Rhizophora mangle diameter at breast height (DBH) size-classes for all structural impact categories and for snapped trees only at La Ventanilla, Oaxaca, southern Mexico, following Hurricane Carlotta of 2012. White bars represent all impact categories (i.e. pre-hurricane structure) and black bars represent snapped stems. Observations were obtained from separate quadrats $(n=64$ individuals per distribution). 
significant difference in distance to nearest-neighbour between structural impact categories of either species (lowest $P$ found $>0.28$ ). For snapped $R$. mangle, thicker trees were likely to snap higher up $\left(r_{s}=0.56, P<0.001\right)$ and trees with higher root systems also snapped higher up $\left(r_{s}=0.39, P<0.001\right)$.

\section{Discussion}

An initial inventory of coastal Oaxaca identified seven lagoons [22], while a more detailed exploration revealed thirteen areas of mangrove habitat [20]. In fact, the Oaxacan coast has many small, and often seasonal, lagoons, which are habitat for mangrove. In this context, the fine scale of the present study reflects the characteristics of the region and this has some relevance when considering sample size. A total of 0.1 ha of sample area was obtained over an extension of $2 \mathrm{~km}$, within a mangrove of roughly 170 ha, giving $0.06 \%$ sample coverage. Other studies of hurricane impact on mangroves have obtained between 0.27 ha and 1.63 ha of sample area, however this has been used within a wider spatial context [7-9]. Samples have been taken over an extension of some 120 $\mathrm{km}$ [8] and from areas of mangrove in the order of thousands of hectares $[6,9]$. While it is recognized that a greater sample size would improve the findings on hurricane impact reported in the present study, within the context of this particular coastal lagoon the sample coverage is no less than that obtained in studies of more extensive mangrove forests.

With regard to the results on reforested saplings, the small sample size is the result of limited resources and should be interpreted as preliminary. The observed mortality rate may be representative of the cohort sampled, but the marked fluctuation in water levels has led to great variation in mortality in patches of reforested mangrove. Despite recommendations [19], a deficit of monitoring following mangrove restoration programmes in Oaxaca is the normal circumstance; not the exception (pers. obs.).

The reductions in stem density and basal area for $R$. mangle are within the range of those reported for all species after Hurricane Andrew, whereas reductions of $L$. racemosa are relatively less [6,8]. The observed $L$. $r a$ cemosa stem loss of the present study is also similar to that reported for Hurricane Georges, although the basal area loss is less [9]. In contrast, apparently much more $R$. mangle stem and basal area was lost during Carlotta than Georges, despite the lower category of Carlotta [9].

The $R$. mangle trees were both significantly more structurally impacted than those of L. racemosa and suffered higher mortality, while within the $R$. mangle sample mortality increased with greater structural damage. Trees of $R$. mangle also had a significantly higher $\mathrm{DBH}$, which is unsurprising as this species had been the focus of previous restoration efforts. Although the L. racemosa stands presented a greater proportion of individuals in the lowest DBH class (27\% as opposed to $13 \%$ for $R$. mangle), the similar DBH averages between species may be attributable to a number of mature $L$. racemosa trees that survived Hurricane Pauline. A possible conjecture is that the $L$. racemosa sample indicated less impact from Hurricane Carlotta because of these thicker individuals, as suggested by the observation that trees $>30 \mathrm{DBH}$ are less vulnerable to hurricane impact [6]. However, this is unconvincing as only two L. racemosa trees were of a $\mathrm{DBH}>30 \mathrm{~cm}$. More plausible explanations are the wider scatter of $L$. racemosa girth, greater flexibility among individuals of the lowest DAP class, and the possibility of species-specific wood properties.

Given that higher mortality for $R$. mangle was observed after category 3 Hurricane Georges [9] but not after category 5 Andrew or category 4 Charley [6,7], it seems feasible that $L$. racemosa is more resistant to mortality, but below a certain wind speed threshold. The reports following Hurricane Andrew are inconsistent in this respect, as L. racemosa was also identified as more vulnerable than $R$. mangle at lower wind speeds [8]. However, variability in species composition and damage on a plot by plot basis are thought to have influenced these results, which are based on mixed species samples [8]. The concept of a threshold wind speed has previously been considered for mangroves, and estimated as somewhere between 47 and $51 \mathrm{~m} / \mathrm{s}$ [29].

Existing information suggests that both extremes of the trunk girth range are less vulnerable to hurricane damage [6,7]. Specifically, $R$. mangle trees of $>35 \mathrm{~cm}$ $\mathrm{DBH}$ were found to be more resistant [9]. Despite the absence of $R$. mangle trees of this girth in the sample from La Ventanilla, the significant difference between DBH distributions of snapped trees and pooled impact categories suggests that mortality is segregated across tree size. Furthermore, trees below $10.5 \mathrm{~cm} \mathrm{DBH}$ were less vulnerable, while those between $12.5 \mathrm{~cm}$ and 18.5 cm were more so (Figure 2).

Corroborating this distinction between size classes is the observation that snapped $R$. mangle trees were statistically thicker than fallen or standing individuals. An obvious reason for this result is the greater flexibility of trees with lesser girth. However, the positive relationship between tree girth and the height of snapping offers an additional explanation: the girth of trunk which a given force is capable of snapping is located at a higher and more exposed position for thicker trees, hence, trees of greater girth snap first. To pursue this enquiry it would be necessary to take data on trunk diameter at the point of snapping, rather than breast height, in order to search for a breakage threshold. The observed positive relationship between the height of the root system and height of 
snapping may be indicative of a structural interaction between the anchorage system and the response to stress, but is more likely a result of covariation with tree growth.

From the perspective of ecological resilience, the great structural alteration of La Ventanilla mangroves by Hurricane Pauline posed a shift in the stability domain of this system, and the chosen response of the managing entity was to try to return the system to the previous, desired state through restoration [4]. They were largely successful in this endeavour, which recommends the course of action they took over the other two available options: foregoing the social benefits of the mangrove and waiting to see if it would regenerate naturally, or adapting to the new stability domain by finding a new land-use for the now cleared land [4]. In the present context, the same managing entity may well repeat their decision and actively manage the mangrove in order to restore it to the desired state, particularly as ecotourism in the mangrove has become central to the local economy [19].

Notwithstanding the above, reviewing the restored mangroves' response to Hurricane Carlotta may help to guide any ensuing conservation restoration protocol. A critical question is whether Hurricane Carlotta impacted stands of $R$. mangle heavily because they had been restored, as opposed to the naturally regenerated $L$. racemosa stands. The intensive planting of saplings after Hurricane Pauline produced structurally homogenous stands of $R$. mangle, which is an attribute that may reduce susceptibility to wind damage as there are fewer over-canopy giants and because the reduced surface roughness reduces turbulence [6]. Although this observation suggests that previous forest management did not increase the hurricane damage sustained, it remains speculative.

Managing the mangrove ecosystem by replanting with $R$. mangle leads to a loss of functional diversity, with an attendant loss of resilience and an increased probability of a shift to an irreversible state [3]. Greater resistance of L. racemosa to wind damage could be a valuable attribute in future restoration efforts. Furthermore, there is evidence that the presence of $L$. racemosa could reduce the hurricane impact sustained by $R$. mangle trees. Taking naturally occurring associations as reference, $R$. mangle mortality has proved lower in L. racemosa dominated stands, or where it occurred in association with this species, than in mono-specific patches [9]. This would suggest that $R$. mangle trees should be interspersed with $L$. racemosa or planted in mono-specific stands between patches of restored or naturally occurring L. racemosa. At a landscape level, restoration of riparian forests around the mangrove could provide a similar buffering function.

The degree of species-specific impact sustained has implications for the rate of regeneration following a hurricane, and these differences may be accentuated by a greater ability to re-sprout from epicormic shoots in $L$. racemosa [9]. Although a quantitative appraisal of regeneration is beyond the scope of the present study, one year of monthly reference photographs following Hurricane Carlotta showed extensive foliage returning to the surrounding tropical dry forest within one month and to $L$. racemosa stands after three months. Mature $R$. mangle trees that remained alive and standing showed some recovery after four months and extensive regrowth after six months. However, these isolated individuals were surrounded by dead wood and vulnerable to further wind impact due to their exposed position (pers. obs.). Reforested $R$. mangle trees planted after 2006 either did not lose their leaves or they were regained very rapidly. The difference in the response of $L$. racemosa and $R$. mangle patches over one year highlights the significance of temporal scale in the regeneration process.

At an annual scale $L$. racemosa and $R$. mangle overlap in the ecological function of processes such as leaf production and nutrient uptake, and this overlap provides stability in the face of population fluctuations of one or other species [30]. On an inter-annual scale, the apparent greater resilience of $L$. racemosa to extreme meteorological events could provide a cross-scale functional reinforcement that increases the resilience of the mangroves as a functional group [30]. Ecosystem management that applies fixed, scale-independent rules can lead to loss of resilience, and the heavy impact sustained by the restored $R$. mangle stands during Hurricane Carlotta may be an example of a breakdown in the face of a disturbance that would previously have been absorbed [3].

In La Ventanilla the hydrological dynamic is highly stochastic at an annual scale (Figure 1), and this lagoon is not unique in presenting extreme variation in water level due to opened and closed inlet conditions [22]. The relationship between sapling growth and water level underscores the importance of coastal lagoon hydrological dynamics, retaining water throughout months when rainfall is completely absent. However, unanticipated closure of the tidal inlet or release of accumulated water presents challenges to reforestation programmes, leading to drowning or desiccation of saplings, respectively.

Recruitment, whether natural or managed, is a key process that structures mangrove stands and is therefore of added importance for maintaining ecological resilience [4]. The relatively low impact of Hurricane Carlotta on the 2007 cohort illustrates the advantage of having mangrove stands of different ages within a local area. By taking into account annual hydrological processes and inter-annual meteorological phenomena, a conservation restoration protocol that adds resilience to this managed mangrove could be successfully implemented. 


\section{Conclusion}

Despite limited experience with hurricane impacts in the region, the mangrove of La Ventanilla has become a managed natural resource because of these catastrophic events. Within the mangrove, the main effect of Hurricane Carlotta was evident in relatively high reductions in stem density and basal area in stands of $R$. mangle. For this species, trees of greater $\mathrm{DBH}$ were more prone to snapping; an effect that may be due to increased brittleness in thicker trunks, but that may also be influenced by the increased height at which girth is vulnerable to snapping. Promising restoration strategies include engendering a mosaic of mangrove stand at different successional stages, increasing the supply of $L$. racemosa saplings through production in nurseries, interspersing $R$. mangle and $L$. racemosa stands, incorporating evenly mixed stands of both species and creating buffers of riparian tropical trees alongside areas of restored mangroves.

\section{Acknowledgements}

This research was made possible by funding from the Consejo Nacional de Ciencia y Tecnología of Mexico. Thanks are given to Laurentino Reyes Sánchez, Venancio Soriano Hernández, Jamie Cooper and Junius Karr for support during field work, and also to Ruben Martínez Camilo for his assistance.

\section{REFERENCES}

[1] E. Lugo, "Conserving Latin American and Caribbean Mangroves: Issues and Challenges,” Madera y Bosques, Vol. 8, Special Issue, 2002, pp. 5-25.

[2] S. C. Snedaker and E. J. Lahman, "Mangrove Understorey Absence: A Consequence of Evolution?” Journal of Tropical Ecology, Vol. 4, No. 10, 1988, pp. 311-314. http://dx.doi.org/10.1017/S0266467400002881

[3] C. S. Holling, "Engineering Resilience versus Ecological Resilience,” In: P. C. Schulze, Ed., Engineering within Ecological Constraints, National Academy Press, Washington DC, 1996, pp. 31-44.

[4] L. H. Gunderson, "Ecological Resilience-In Theory and Application," Annual Review of Ecology and Systematics, Vol. 31, 2000, pp. 425-439. http://dx.doi.org/10.1146/annurev.ecolsys.31.1.425

[5] E. Lugo and R. B. Waide, "Catastrophic and Background Disturbance of Tropical Ecosystems at the Luquillo Experimental Forest," Journal of Bioscience, Vol. 18, No. 4, 1993, pp. 475-481. http://dx.doi.org/10.1007/BF02703080

[6] T. J. Smith, M. B. Robblee, H. R. Wanless and T. W. Doyle, "Mangroves, Hurricanes, and Lightning Strikes," BioScience, Vol. 44, No. 4, 1994, pp. 256-262. http://dx.doi.org/10.2307/1312230

[7] E. C. Milbrandt, J. M. Greenawalt-Boswell, P. D. Sokoloff and S. A. Bortone, "Impact and Response of South- west Florida Mangroves to the 2004 Hurricane Season," Estuaries and Coasts, Vol. 29, No. 6, 2006, pp. 979-984.

[8] T. W. Doyle, T. J. Smith and M. B. Robblee, "Wind Damage Effects of Hurricane Andrew on Mangrove Communities along the Southwest Coast of Florida, USA," Journal of Coastal Research, Special Issue No. 21, 1995, pp. 159-168.

[9] R. E. Sherman, T. J. Fahey and P. Martinez, "Hurricane Impacts on a Mangrove Forest in the Dominican Republic: Damage Patterns and Early Recovery," Biotropica, Vol. 33, No. 3, 2001, pp. 393-408.

[10] J. W. Wiley and J. M. Wunderle, "The Effects of Hurricanes on Birds, with Special Reference to Caribbean Islands," Bird Conservation International, Vol. 3, No. 4, 1993, pp. 319-349. http://dx.doi.org/10.1017/S0959270900002598

[11] R. Valdez, J. C. Gúzman-Aranda, F. J. Abarca, L. A. Tarango-Arámbula and F. C. Sánchez, "Wildlife Conservation and Management in Mexico," Wildlife Society Bulletin, Vol. 34, No. 2, 2006, pp. 270-282. http://dx.doi.org/10.2193/0091-7648(2006)34[270:WCA MIM]2.0.CO;2

[12] J. Maass, et al., "Ecosystem Services of Tropical Dry Forests: Insights from Long-Term Ecological and Research on the Pacific Coast of Mexico," Ecology and Society, Vol. 10, No. 1, 2005, p. 17.

http://www.ecologyandsociety.org/vol10/iss1/art17/

[13] E. J. Farnsworth and A. M. Ellison, "The Global Conservation Status of Mangroves,” Ambio, Vol. 26, No. 6, 1997, pp. 328-334.

[14] Navarro-Martínez, R. Durán-García and M. MéndezGonzález, "The Impact of the Hurricane Dean on the Structure and Arboreal Composition of a Managed Forest in Quintana Roo, Mexico,” Madera y Bosques, Vol. 18, No. 1, 2012, pp. 57-76.

[15] U. L. Kaly and G. P. Jones, "Mangrove Restoration: A Potential Tool for Coastal Management in Tropical Developing Countries,” Ambio, Vol. 27, No. 8, 1998, pp. 656-661.

[16] E. B. Barbier, "Natural Barriers to Natural Disasters: Replanting Mangroves after the Tsunami," Frontiers in Ecology and the Environment, Vol. 4, No. 3, 2006, pp. 124-131.

http://dx.doi.org/10.1890/1540-9295(2006)004[0124:NB TNDR]2.0.CO;2

[17] M. B. Lawrence, “Tropical Cyclone Report Hurricane Pauline 5-10 October 1997,” The National Hurricane Center, Miami, 1997.

[18] M. Mayfield, “Tropical Cyclone Report Hurricane Rick 7-10 November 1997,” The National Hurricane Center, Miami, 1997.

[19] Foucat, "Community-Based Ecotourism Management Moving towards Sustainability, in Ventanilla, Oaxaca, Mexico,” Ocean \& Coastal Management, Vol. 45, No. 8, 2002, pp. 511-529. http://dx.doi.org/10.1016/S0964-5691(02)00083-2

[20] T. Hernández, F. O. Estrada, J. C. de la Presa Pérez and D. T. G. Castillo, “Segundo Informe: Inventario y Monitoreo 
del Estado Actual de los Bosques de Manglar de Chiapas y Oaxaca," Laboratorio de Ecología de Manglares y Zonas Costeras, El Colegio de la Frontera Sur-unidad Tapachula, 2010.

[21] R. J. Pasch and D. A. Zelinsky, "Tropical Cyclone Report (EP032012) Hurricane Carlotta 14-16 June,” National Hurricane Center, Miami, 2012.

[22] R. R. Lankford, “Coastal Lagoons of Mexico, Their Origin and Classification,” Estuarine Processes, Vol. 2, 1977, pp. 182-215.

[23] N. Pérez-Morga, T. Kretzschmar, T. Cavazos, S. V. Smith and F. Munoz-Arriola, "Variability of Extreme Precipitation in Coastal River Basins of the Southern Mexican Pacific,” Geofisica International, Vol. 52, No. 3, 2013, pp. 277-291.

[24] I. Trejo, “Clima,” In: A. J. Garcia-Mendoza, M. J. de Jesús Ordóñez and M. Briones-Salas, Eds., Biodiversidad de Oaxaca, Instituto de Biología UNAM/Fondo Oaxaqueño Para la Conservación de la Naturaleza/World Wildlife Fund, México D.F., 2004, pp. 67-85.

[25] E. Medina, "Mangrove Physiology: The Challenge of Salt, Heat, and Light Stress under Recurrent Flooding," In: A. Yáñez-Arancibia and A. L. Lara-Domínguez, Eds. Ecosistemas de Manglar en América Tropical, Instituto de Ecología AC México, UICN/ORMA Costa Rica, NOAA/ NMFS Silver Spring MD USA, Xalapa, 1999, pp. 109-
126.

[26] F. J. Flores-Verdugo, F. González-Farías, D. S. Zamorano and P. Ramírez-García, "Mangrove Ecosystems of the Pacific Coast of Mexico: Distribution, Structure, Litterfall, and Detritus Dynamics,” In: U. Seelinger, Ed., Coastal Plant Communities of Latin America, Academic Press Inc., San Diego, 1992, pp. 269-288. http://dx.doi.org/10.1016/B978-0-08-092567-7.50023-4

[27] C. Agraz-Hernández, R. Noriega-Trejo, J. López-Portillo, F. J. Flores-Verdugo and J. J. Jiménez-Zacarías, "Guía de Campo: Identificación de los Manglares en México,” CENTRO EPOMEX-UAC, Campeche, 2006.

[28] P. J. Clark and F. C. Evans, "Distance to Nearest Neighbour as a Measure of Spatial Relationships in Populations,” Ecology, Vol. 35, No. 4, 1957, pp. 445-453. http://dx.doi.org/10.2307/1931034

[29] P. G. E. F. Augustinus, "Geomorphology and Sedimentology of Mangroves,” In: G. M. E. Perillo, Ed., Geomorphology and Sedimentology of Estuaries, Elsevier Science B.V., Amsterdam, 1995, pp. 333-357. http://dx.doi.org/10.1016/S0070-4571(05)80032-9

[30] G. Peterson, C. R. Allen and C. S. Holling, "Ecological Resilience, Biodiversity, and Scale,” Ecosystems, Vol. 1, No. 1, 1998, pp. 6-18. http://dx.doi.org/10.1007/s100219900002 